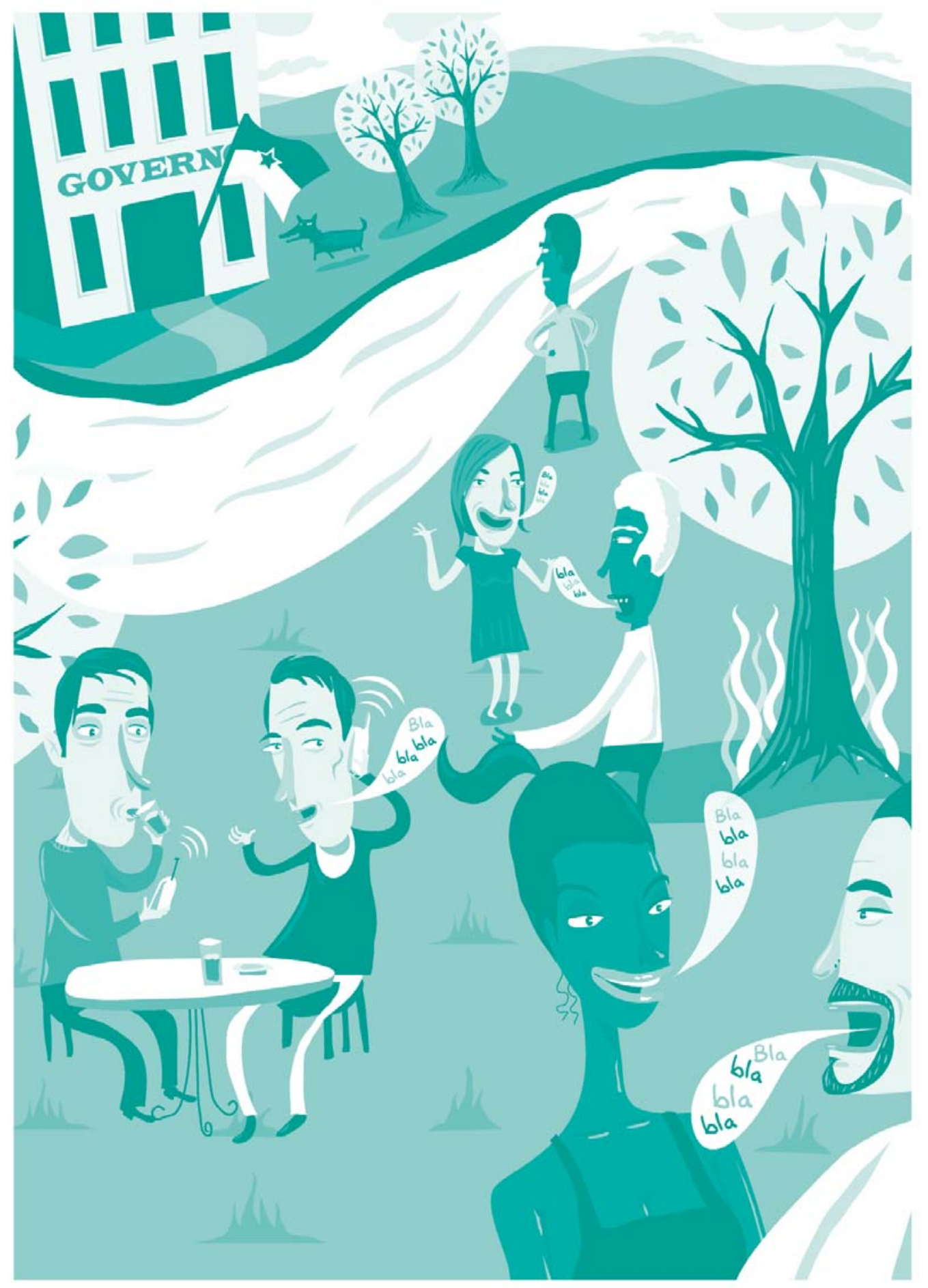




\section{O papel institucional da Comunicação Pública para o sucesso da governança}

Ana Lucia Coelho Romero Novelli

- Doutora em Ciências da Comunicação pela Escola de Comunicações e Artes da Universidade de São Paulo (ECA-USP)

- Mestre em Comunicação pela Universidade de Brasília (UnB)

- Graduada em Comunicação Social pela Universidade Estadual de Londrina (UEL)

- Diretora da Secretaria de Pesquisa e Opinião Pública do Senado Federal

- Ganhadora, em 2003, do Prêmio Opinião Pública, conferido pelo Conselho Regional de Profissionais de Relações Públicas - $2^{\mathrm{a}}$ Região e, em 2000, do Prêmio Intercom 2000 - Modalidade Relações Públicas, conferido pela Sociedade Brasileira de Estudos Interdisciplinares da Comunicação (Intercom)

- novelli@senado.gov.br

- alnovelli@uol.com.br 
Resumo

Compreender a amplitude do termo governança, nos dias atuais, é o mesmo que buscar a reinvenção do setor público por meio da alteração de sua consciência e modo de atuação. Como forma objetiva de operacionalização dessa mudança, a comunicação que se pratica pelas instituições e órgãos públicos se apresenta como instrumental valioso para o fortalecimento da esfera pública e dos mecanismos de democratização e participação cidadã.

PALAVRAS-CHAVE: GOVERNANÇA - COMUNICAÇÃo PÚblica • PARTICIPAÇÃo - ACCOUNTABILITY - CIDADANIA

\section{Abstract}

Understanding the magnitude of the term governance is currently like searching for the reformulation of the public sector structure, which implies changes in its awareness and acting mode. As an objective way of achieving these changes, the communication used by institutions and government offices presents itself as a valuable tool for strengthening the public sphere and the participation of citizens, as well as democratization mechanisms.

KEYWORDS: GOVERNANCE • PUBLIC COMUNICATION • PARTICIPATION • ACCOUNTABILITY • CITZENSHIP

\section{Resumen}

Comprender la amplitud del término gobernabilidad, en los días actuales, es lo mismo que buscar la reformulación de la estructura del sector público, por medio de la modificación de su conciencia y modo de actuación. Como forma objetiva de poner en práctica ese cambio, la comunicación que se ejerce por las instituciones y por los órganos gubernamentales se presenta como valioso instrumento para el fortalecimiento de la esfera pública y de los mecanismos de democratización y participación ciudadana.

PALABRAS CLAVES: GOBERNABILIDAD - COMUNICACIÓN PÚBLICA • PARTICIPACIÓN • RESPONSABILIDAD - CIUDADANÍA 
$\mathrm{O}$ mundo vive em ritmo frenético de transformações econômicas, políticas e sociais e, para acompanhar tal velocidade, novas práticas de comunicação são constantemente incorporadas ao repertório dos profissionais e pesquisadores da área que se debruçam sobre a ação e a gestão da comunicação na esfera do Estado brasileiro. Um desses exemplos é a proximidade entre as formas de governança advindas do modelo de Reforma do Estado implantado no Brasil a partir dos anos 90 e a área de comunicação pública.

Como em grande parte das sociedades ocidentais, o governo brasileiro também foi obrigado a desenvolver uma ampla reforma do Estado para buscar maior sintonia entre o seu modelo de gestão e o novo ambiente mundial configurado pelo capitalismo neoliberal que se disseminou como corrente dominante após a queda do comunismo. Dentre todas as possíveis vertentes de análise da Reforma do Estado brasileiro, a que mais interessa a este artigo é a perspectiva das novas formas de participação política efetivamente colocadas à disposição da sociedade para que o cidadão possa realizar intervenções na gestão de políticas públicas.

A partir das formas de governança instituídas pela Constituição de 1988 e da Reforma do Estado realizada na década seguinte, a comunicação pública, ou seja, aquela comunicação praticada pelos órgãos responsáveis pela administração pública, assume na prática uma importância significativa para o exercício da participação política e da cidadania. Cabe à comunicação pública, nesse contexto, extrapolar a esfera da divulgação de informações do governo e da assessoria de imprensa como mecanismo de autopromoção dos governantes e de suas ações para colocar-se como instrumento facilitador do relacionamento entre cidadão e Estado.

Nesse sentido, a proposta do artigo é analisar de forma contextualizada o papel da comunicação pública nas mudanças sofridas pelo Estado brasileiro em seu processo de reforma e os impactos dessa nova configuração nos processos de governança, participação e cidadania.

\section{A crise do Estado em tempos de modernidade líquida}

Muito já se falou, nos últimos tempos, sobre as mudanças de paradigma e suas conseqüências para a sociedade. Longe de se mostrar como uma abstração teórica de acadêmicos que têm pouca vinculação com a realidade, essa discussão é extremamente 
importante para que se possa compreender o mundo a nossa volta. De acordo com as análises de Zygmunt Bauman (2001), sociólogo polonês, que se tem dedicado a compreender o mundo atual, vivemos em um período de modernidade líquida. Como figura de linguagem, o termo procura contrapor o momento atual com o passado, que pode ser caracterizado como uma fase de modernidade sólida.

O exemplo do líquido se adequa a nossa condição contemporânea, pois ele representa a "fluidez" e "leveza" dos nossos tempos. Os líquidos têm a capacidade de mudar de forma ao sofrer algum tipo de pressão, adaptando-se constantemente ao meio; já o sólido é concebido para não mudar. A rigidez do sólido é tanta que, mesmo retorcido ou flexionado em decorrência de pressão externa, volta à forma original.

A metáfora de Bauman é bastante interessante, na medida em que se vivencia o rompimento e substituição de antigos códigos, padrões e regras. Se há algumas décadas o bom empregado era aquele fiel à companhia e que tinha por objetivo se aposentar na mesma empresa, hoje esse empregado é caracterizado como acomodado e improdutivo. Se antes o casamento era "até que a morte os separe", hoje é "até que o divórcio os encontre".

Mesmo que o derretimento de antigos sólidos seja uma das características da modernidade, a exemplo do ocorrido durante nossas principais revoluções - como a revolução francesa, ou mesmo a revolução comunista, que tinham por objetivo questionar e alterar padrões e comportamentos arraigados nos indivíduos -, o que chama a atenção em nossa modernidade atual é a falta ou a diversidade de opções que se apresentam à sociedade.

Desta vez, não estamos falando simplesmente de mudar um comportamento por outro já predefinido. Isso porque não se tem com tanta clareza "outro comportamento predefinido" para colocar no lugar. Apresenta-se, sim, uma grande diversidade de opções que podem livremente ser escolhidas pelo indivíduo. Dessa forma, a falta de referenciais consolidados é uma das principais características deste tempo atual.

Outro destaque importante refere-se à questão do tempo e do espaço. Enquanto a modernidade sólida ansiava por possuir o espaço e controlar o tempo, a modernidade líquida simplesmente pode atravessar o espaço de forma instantânea, literalmente em “tempo nenhum”. O longe e o perto não são mais categorias determinantes.

Em termos políticos, a modernidade líquida coincide com o esgotamento do modelo de gestão baseado no welfare state, ou Estado de bem-estar social, no qual o Estado assumia posição de destaque na sociedade, seja do ponto de vista econômico, político ou ético.

Esse modelo de Estado, a partir da década de 70, começou a apresentar problemas es- 
truturais e entrou em crise profunda. O pacto político estabelecido e a aliança entre as classes sociais, esta baseada na manutenção das despesas com programas sociais, ruíram quando o Estado não teve mais condições econômicas de viabilizar tal proposta, uma vez que as despesas tornaram-se crescentes e as fontes de riqueza não se desenvolveram no mesmo ritmo.

A alternativa ao Estado provedor da sociedade veio na fórmula do retorno aos princípios da livre regulação pelo mercado e, a partir da década de 80, tem-se o auge do Estado mínimo de inspiração neoliberal.

Atualmente, não se fala mais em Estado mínimo e, sim, num Estado de configuração ótima, cujo tamanho e desenho institucional passam a ser condicionados pelo grande número de circunstâncias que impactam seu desempenho eficiente. O Estado deve interferir na promoção do desenvolvimento econômico, competitividade e eficiência dos mercados nacionais, sem abandonar aspectos relacionados ao bem-estar da sociedade, incluindo o desenvolvimento de mecanismos de participação popular, descentralização e accountability.

\section{Novas práticas para um novo Estado}

A reforma do Estado implica, conseqüentemente, a reforma do aparelho do Estado, ou seja, dos mecanismos e instâncias que estão ligados diretamente à operacionalização das políticas públicas. Tradicionalmente, a burocracia, como forma racional-legal de exercício do poder, tem sido a fonte de legitimação da administração pública. Exaustivamente discutida por Max Weber, a forma de atuação da gestão burocrática baseia-se em princípios como impessoalidade e divisão do trabalho. No que se refere à atuação dos funcionários públicos, a burocracia impacta diretamente o seu desempenho, a partir de características como a definição da hierarquia dos cargos e cadeia de comando de cima para baixo, estabelecimento prévio de atribuições e competências, especialização da mão-de-obra com funcionários estáveis que avançam nas carreiras por critérios corporativos, como tempo de serviço, entre outros.

A organização burocrática da administração pública resultou na formação de uma estrutura auto-referenciada no Estado, baseada em seus próprios interesses e não nas necessidades da sociedade. Esta, contudo, é uma perspectiva conflituosa com o con-

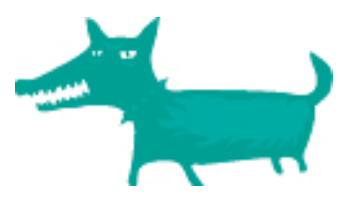


texto democrático que as sociedades conquistaram, pois são exatamente os interesses da sociedade que a democracia deve proteger. Aparentemente, administração e política tornam-se conceitos opostos.

A crise de governabilidade dos Estados, no entanto, demonstrou que a administração burocrática, quando aliada às práticas democráticas de governo, pode produzir resultados muito eficientes. Num Estado comprometido com o bem-estar e os interesses da população, os projetos e programas desenvolvidos pelo governo gozam da racionalidade administrativa da organização burocrática e do apoio popular e legitimidade das práticas democráticas.

"O êxito das políticas governamentais requer não apenas a mobilização dos instrumentos institucionais técnicos, organizacionais e de gestão, controlados por burocratas, mas também de estratégias politicas, de articulação e de coalizações que dêem sustentabilidade e legitimidade às decisões". (BENTO, 2003, p. 85)

Para acompanhar tais transformações, a administração pública também passou por uma série de adaptações. A primeira onda de mudanças, conhecida como gerencialismo, pregava a redução das despesas e aumento da produtividade como elementos de eficiência. A realidade mostrou que o corte de gasto, demissão dos funcionários considerados improdutivos e outras ações do mesmo tipo, por si sós, não conseguem superar os vícios da lógica burocrática.

A crítica ao excesso de auto-referência da administração pública, que pouco se interessava em atender aos usuários dos serviços públicos, gerou a segunda onda de mudanças, chamada de consumerismo. De acordo com essa corrente, a administração pública deve considerar as informações prestadas por seus "clientes" e deve ser descentralizada para estar mais próxima de seu destinatário, o que faz com que os próprios consumidores dos serviços prestados colaborem diretamente na sua fiscalização.

Para Bresser Pereira (1998, p. 118), "ver o administrado como um cliente significa inverter a cultura burocrática auto-referente, de defender-se contra o público, para uma análise heterorreferente, em que todo esforço se dá no sentido de melhor servir o público". Mesmo assim, essa corrente ganhou muitas críticas. A principal delas foi o fato de adotar a visão de "cliente" no lugar de cidadão como destinatário dos serviços públicos. Diferentemente do cliente, o cidadão reivindica o direito de participar ativamente da formulação de políticas públicas e na implementação e gestão dos serviços públicos.

Em sua terceira onda de mudanças, a administração pública busca maior sintonia entre os princípios gerenciais, agora voltados para o cidadão e não apenas para o consumidor dos serviços públicos. Nessa perspectiva, pode-se ressaltar a ênfase na aprendizagem, na valorização da cultura organizacional, na responsabilização (accountability) 
de políticos e administradores, no desenvolvimento da cidadania, na participação popular e na defesa da res publica.

Para Bento (2003, p. 94), "a administração orientada para o cidadão incorpora a preocupação com a qualidade do serviço - que é a tônica da perspectiva anterior - acrescentando, porém, a dimensão ativa da cidadania”. Em complemento a essa análise, o autor continua: "a cidadania considerada nesta perspectiva transcende a dimensão passiva da titularidade de direitos, abrindo-se para a participação e a partilha de poder e de responsabilidade entre administração pública e o público”.

Não se pode afirmar que essas propostas estejam presentes de maneira uniforme nos vários países; no entanto, é possível reconhecer um conjunto coerente de novas propostas caracterizando uma revolução gerencial na administração pública.

\section{O Estado se abre para a governança}

Democracia e eficiência são conceitos que passam a se interligar de maneira muito próxima a partir da perspectiva do novo modelo de gestão pública que pressupõe que o Estado é tão mais eficiente quanto mais democrática for a sua administração.

"Acredita-se que os governos que asseguram a participação dos cidadãos na formulação, implantação e implementação de políticas públicas, graças à sustentabilidade política e legitimidade que logram obter para seus programas de ação, tornam-se muito mais eficientes do que poderia ser qualquer equipe de tecnocratas altamente especializados e insulados frente à população, na medida em que contam com o apoio desta enfraquecendo as resistências da oposição, evitando o desgaste político de intervenções autoritárias". (BENTO, 2003, p. 219)

As estratégias governamentais têm-se esforçado para desenvolver novos mecanismos de governança que possibilitem uma influência maior da sociedade nos assuntos públicos, inclusive por meio de participação direta em muitos casos.

De forma geral, a governança se refere aos pré-requisitos institucionais para a otimização do desempenho administrativo - instrumentos técnicos de gestão que assegurem a eficiência e a democratização das políticas públicas. Já a governabilidade, que para muitos autores é a outra face da moeda da governança, refere-se à capacidade do Estado de obter apoio e articular alianças entre os vários grupos sociais com o objetivo de viabilizar a implementação de seu projeto de Estado.

Buscando uma síntese dos autores que discutem as diferentes perspectivas do conceito de governabilidade e governança no Brasil, Araújo (2002, p. 19) elaborou um quadrosíntese com a posição de três autores de expressão: Bresser Pereira, Eli Diniz e Caio Marini. 


\begin{tabular}{|l|l|l|l|}
\hline Autores & Governabilidade & Governança & Traço/Distintivo \\
\hline Bresser Pereira & $\begin{array}{l}\text { Capacidade de governar } \\
\text { derivada da relação de } \\
\text { legitimidade do Estado } \\
\text { e do seu governo com } \\
\text { a sociedade civil. }\end{array}$ & $\begin{array}{l}\text { Capacidade } \\
\text { financeira/gerencial } \\
\text { de formular e } \\
\text { implementar } \\
\text { políticas públicas. }\end{array}$ & $\begin{array}{l}\text { Énfase na governança. Entende } \\
\text { a governabilidade como } \\
\text { garantia nos seus fundamentos } \\
\text { por meio do processo de } \\
\text { redemocratização recente. }\end{array}$ \\
\hline Eli Diniz & $\begin{array}{l}\text { Condições sistêmicas } \\
\text { de exercício de poder } \\
\text { pelo Estado e seu } \\
\text { governo em uma } \\
\text { determinada sociedade. }\end{array}$ & $\begin{array}{l}\text { Capacidade de } \\
\text { ação do Estado } \\
\text { na formulação e } \\
\text { implementação de } \\
\text { políticas públicas } \\
\text { e consecução das } \\
\text { metas coletivas. }\end{array}$ & $\begin{array}{l}\text { Énfase da conexão da temática } \\
\text { com a reforma do Estado, } \\
\text { institucionalização da } \\
\text { democracia e, em especial, } \\
\text { com o incremento da } \\
\text { participação dos cidadãos. }\end{array}$ \\
\hline Caio Marini & $\begin{array}{l}\text { Condições de } \\
\text { legitimidade de um } \\
\text { determinado governo } \\
\text { para empreender } \\
\text { as transformações } \\
\text { necessárias. }\end{array}$ & $\begin{array}{l}\text { Capacidade técnica, } \\
\text { financeira } \\
\text { e gerencial } \\
\text { de implementar } \\
\text { transformações. }\end{array}$ & $\begin{array}{l}\text { Enfase na ligação da temática } \\
\text { com a reforma do Estado } \\
\text { e com a superação das } \\
\text { desigualdades estruturais } \\
\text { da sociedade brasileira. }\end{array}$ \\
\hline
\end{tabular}

A análise comparativa dessas perspectivas demonstra certa convergência entre os autores, pois compreendem a governabilidade como a capacidade do Estado de exercer o poder legitimamente, enquanto a governança refere-se à forma adotada pelo Estado para implementar seus projetos. A ênfase concedida pelos autores à governança deve-se a sua enorme capacidade democrática de estimular e viabilizar a participação efetiva da sociedade na elaboração e condução das políticas públicas.

\section{Quadro 1. Relação entre governança e democracia}

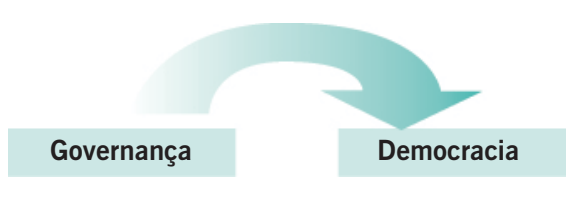

Os governos que asseguram a participação dos cidadãos na formulação e implementação de políticas tornam-se mais eficientes na medida em que estas políticas alcançam maior sustentabilidade política e legitimidade.
As estratégias governamentais para uma governança eficiente tornam o Estado mais permeável à influência da sociedade, seja pela participação direta, seja pela representação. 
A prática da governança tem-se baseado em três mecanismos fundamentais: instrumentos de democracia direta, instrumentos de representação e o terceiro setor. Entre os instrumentos de democracia direta estão o referendo, o plebiscito e a iniciativa popular na elaboração das leis. Previstos em nossa Constituição, esses mecanismos são de uso extraordinário e caracterizam um momento de exceção da vida política do país. Não é viável que para tomar uma decisão o Estado precise da concordância expressa de cada indivíduo, mas em casos especiais é importante que a sociedade se manifeste.

A grande vantagem desses mecanismos de democracia direta é que eles são capazes de conviver de forma bastante construtiva com os demais. O Congresso Nacional tem recorrido a tais mecanismos na história recente do país, a exemplo do plebiscito sobre a forma e regime de governo, em 1993, e o referendo sobre o porte de armas, ocorrido em 2005. A Lei 9.840, de 1999, que trata da tipificação do crime de compra de votos por candidatos a cargos eletivos, foi elaborada a partir da iniciativa popular, em um movimento capitaneado pela Conferência Nacional dos Bispos do Brasil (CNBB) e pela Ordem dos Advogados do Brasil (OAB). Para facilitar a sugestão de novas leis pela sociedade, tanto a Câmara dos Deputados quanto o Senado Federal criaram comissões parlamentares específicas que têm a incumbência de analisar e apresentar as propostas de iniciativa popular.

Por outro lado, quando se trata de aplicar os instrumentos de governança no ambiente da democracia representativa, tem-se uma forte tendência a adotar o formato do controle comunitário na administração pública. Esse controle pode se dar de maneira resolutiva, como a criação de conselhos que auxiliam na gestão das políticas públicas, a exemplo dos vários conselhos que estão ativos em todo país, principalmente na esfera municipal. A maior vantagem desse tipo de participação é que ela é capaz de agregar a experiência e a proximidade dos próprios cidadãos que utilizam os serviços públicos.

O controle comunitário também pode se dar de forma consultiva, quando o cidadão é convidado a expressar sua opinião sobre os variados temas públicos. Os conselhos consultivos existentes em várias esferas de poder são exemplos desse mecanismo, bem como as audiências públicas e as pesquisas de opinião. Nesses casos, o objetivo é estabelecer canais de feedback com a sociedade para que as ações públicas possam ser readequadas de acordo com o ponto de vista dos cidadãos, e não apenas a partir da lógica burocrática tradicional.

O terceiro setor, segundo a perspectiva da governança, tem desempenhado um papel de destaque no que se refere às Organizações da Sociedade Civil de Interesse Público (Oscip). Estas organizações assumem determinados contratos de gestão que transferem a elas a responsabilidade de executarem serviços públicos. Como elas não fazem parte do Estado e também não fazem parte do mercado, as entidades do terceiro setor transitam com mais liberdade no interior da sociedade civil. 
"O terceiro setor aparece como campo privilegiado para a atividade social, não em virtude de suas potencialidades emancipatórias, mas por motivos de eficiência, eis que logra aliviar o Estado das demandas populares, do custo das políticas públicas de distribuição, ao mesmo tempo em que pode operar com maior autonomia e flexibilidade gerencial". (BENTO, 2003, p. 237)

Internacionalmente, a discussão sobre governança aponta para a necessidade dos governos se adaptarem a uma nova realidade mais participativa e inclusiva. A Organização para Cooperação e Desenvolvimento Econômico (OCDE), entidade que congrega 30 países desenvolvidos, usa o termo governança "para descrever como a autoridade é distribuída no sistema governamental e como as pessoas que detêm tal autoridade são responsabilizadas" (KONDO, 2002, p. 11). Entre os países membros da entidade, a boa governança inclui o respeito a três aspectos: a responsabilização dos agentes públicos por suas ações; a transparência das ações e informações que são disponibilizadas aos cidadãos; e a abertura dos governos para escutar a opinião dos cidadãos e das empresas e considerá-la na formulação das políticas públicas.

Para estimular o engajamento dos cidadãos e estimular maior participação, é preciso que os governos sigam dez princípios orientadores para o desenvolvimento de mecanismos sólidos de governança (KONDO, 2002, p. 288):

1 - Compromisso - é preciso obter o comprometimento dos envolvidos, desde a classe política e a alta administração governamental até os próprios funcionários públicos.

2 - Direitos - o acesso à informação e as possibilidades de participação devem estar ancoradas em leis claras e objetivas.

3 - Clareza - as funções e responsabilidades dos cidadãos e do governo em contribuir para a discussão e tomada de decisão devem ser explícitas.

4 - Prazo - é preciso estabelecer prazo suficiente para que as discussões possam surgir e se consolidar ao longo do processo de debate.

5 - Objetividade - as informações fornecidas pelo governo aos cidadãos devem ser objetivas, completas e acessíveis a todos.

6 - Recursos - o governo deve alocar os recursos necessários para o desenvolvimento dos mecanismos de governança, incluindo o treinamento e a capacitação de funcionários públicos.

7 - Coordenação - as iniciativas que demandam a participação do cidadão precisam ser coordenadas nas várias esferas do governo para não haver o risco de ocorrer uma "fadiga por excesso de consulta".

8 - Responsabilidade - o governo precisa prestar contas das contribuições oferecidas pelo cidadão e, portanto, deve-se investir em mecanismos que sejam abertos, transparentes e de fácil fiscalização.

9 - Avaliação - são necessários instrumentos de avaliação dos mecanismos de governança, a fim de verificar sua eficácia junto aos cidadãos. 
O PAPEL INSTITUCIONAL DA COMUNICAÇÃO PÚBLICA PARA O SUCESSO DA GOVERNANÇA • ANA LUCIA C. ROMERO NOVELLI

10 - Cidadania Ativa - um dos maiores beneficiários da cidadania ativa é o próprio governo, que conta com a ampliação da capacidade cívica da sociedade e passa a implementar seus projetos a partir de prévio processo de legitimação dos cidadãos.

\section{A Comunicação Pública para a prática da governança}

Muitos países têm atribuído a integridade de suas instituições públicas e a capacidade de seus processos democráticos em garantir os interesses e bem-estar dos cidadãos à implantação de elevados padrões de governança. É preciso fortalecer as relações com os cidadãos e estimular sua participação para aumentar a confiança pública no governo, melhorar a qualidade da democracia e a capacidade cívica da população. De acordo com Kondo, "o engajamento ativo dos cidadãos pode assegurar que as políticas públicas sejam apoiadas ou pelo menos compreendidas pelo público de modo a contribuir para a sua efetiva implementação" (2002, p. 15). Dessa forma, o papel da comunicação pública no processo de apoio às práticas da boa governança é decisivo para o sucesso da proposta.

A comunicação pública, compreendida como o processo de comunicação que ocorre entre as instituições públicas e a sociedade e que tem por objetivo promover a troca ou o compartilhamento das informações de interesse público, passa a desempenhar um papel importante de mediação para as práticas de boa governança.

Considerando que o relacionamento entre governo e cidadão na definição das políticas públicas envolve relações comunicativas em todas as suas etapas, desde a concepção até a avaliação, Kondo (2002, p. 283) propõe a seguinte caracterização dos fluxos comunicacionais existentes entre governo-cidadão:

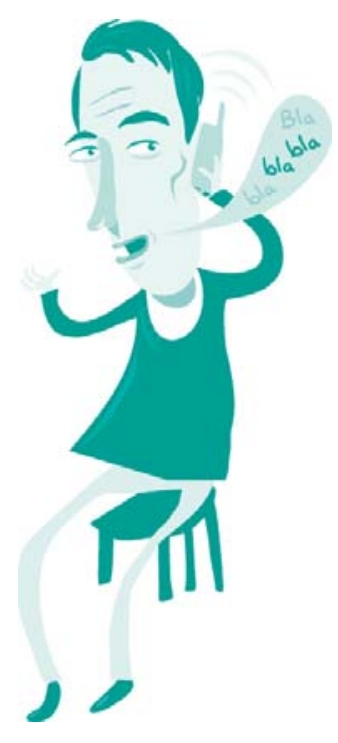


Informação: Relação de mão única em que o governo fornece informações aos cidadãos. Refere-se tanto ao acesso "passivo" do cidadão em face de informações demandadas, quanto às medidas "ativas" do governo para divulgação da informação aos cidadãos.

\section{GOVERNO $\Rightarrow$ CIDADÃO}

Consulta: Relação de mão dupla em que os cidadãos oferecem feedback ao governo. Baseia-se na definição prévia dos temas sobre os quais o governo solicitará que o cidadão opine.

\section{GOVERNO CIDADÃO}

Participação ativa: Relação que se baseia na parceria com o governo, em que os cidadãos se engajam diretamente na formulação das políticas públicas e têm reconhecido o seu papel na proposição de opções.

\section{GOVERNO $\Leftrightarrow$ CIDADÃO}

Como se percebe, o próprio fluxo de comunicação acaba caracterizando o nível de relacionamento entre o governo e o cidadão. Essa inter-relação é muito próxima, pois o principal objetivo da comunicação pública, quando se aplica a prática da governança, é promover e viabilizar o relacionamento mais interativo e participativo entre governantes e governados.

Ao analisar o modelo em que o fluxo de comunicação se baseia no processo de informação, percebe-se que a comunicação é descendente, tendo o governo como emissor e o cidadão como receptor. O grau de envolvimento da sociedade é pequeno e a participação é discreta. Neste modelo estão duas propostas de comunicação que são bastante usadas:

a) o modelo de comunicação de massa, principalmente aquele formatado a partir da perspectiva da mensagem publicitária e assessoria de imprensa, e que pretende alcançar grande quantidade de receptores em áreas geográficas dispersas;

b) a disponibilização de dados públicos, baseada na perspectiva do direito do cidadão de acessar informações de caráter público que estão sob a guarda do governo e que esclareçam as "regras do jogo coletivo", tanto em relação ao quadro legal quanto aos procedimentos que devem ser adotados pelos cidadãos em seus relacionamentos com os órgãos públicos.

No modelo em que o fluxo de comunicação privilegia a forma de consulta, o processo de comunicação é horizontalizado e a opinião dos cidadãos é solicitada pelo governo como feedback. Embora possa utilizar ferramentas de comunicação dirigida, a pers- 
pectiva de fundo neste modelo é de que quem define a agenda temática dos assuntos a serem discutidos é o governo, e não o cidadão.

Essa assimetria entre os atores sociais no processo comunicativo provoca um nível relativo de participação do cidadão. Entre as formas de comunicação mais utilizadas neste nível, estão as audiências públicas, as iniciativas de controle comunitário, como os conselhos consultivos e, também, as pesquisas de opinião. Conhecer a opinião dos cidadãos é, assim, um elemento a mais a ser considerado durante a elaboração e a definição das políticas públicas.

O modelo de participação ativa do cidadão pressupõe um processo de comunicação horizontal baseado na parceria e no estímulo ao engajamento da sociedade na formulação de políticas públicas. As novas tecnologias da informação e comunicação, que privilegiam a interação entre os atores sociais independentemente de suas localizações geográficas, são ferramentas valiosas para a viabilização da participação mais ativa do cidadão. Este é um modelo de comunicação que ainda está em fase experimental em vários países. No Brasil, a experiência de elaboração do orçamento participativo em algumas prefeituras tem demonstrado o êxito da iniciativa, que tem seu foco na participação deliberativa sobre os investimentos e fiscalização dos gastos públicos por parte da sociedade.

Independentemente do modelo de comunicação a ser adotado em cada proposta, a comunicação deve ser planejada e executada de forma a facilitar o intercâmbio dos atores sociais envolvidos em cada iniciativa. Ancorado nos mecanismos de governança, o processo de comunicação deixa de ser compreendido como apenas um instrumento de disseminação das ações e políticas públicas e passa a ser concebido como parte intrínseca dos projetos e programas desenvolvidos pelo governo. Esse tipo de comunicação está mais envolvido com a promoção da cidadania e da participação do que com a divulgação institucional.

Para obter essa maior interação, já durante a definição dos objetivos a serem atingidos e o escopo da proposta a ser implantada, o projeto passa a ser concebido incluindo as suas potencialidades de promoção da comunicação. A simbiose entre objetivos do projeto e objetivos da comunicação do projeto é integral.

Após essa etapa inicial, deve haver a identificação precisa do público-alvo do projeto. Mesmo que, em termos gerais, o público da comunicação praticada por órgãos públicos seja toda a sociedade, é importante que cada projeto defina claramente com quem quer estabelecer um maior relacionamento, pois é esse grupo que passará a ser o foco principal do processo de comunicação a ser deflagrado. Os grupos sociais, nesses casos, podem ser amplos e genéricos quando se referirem à população como um todo, ou então podem ser restritos e dirigidos, quando se dirigirem a grupos menores, como os moradores de determinada região ou segmentos específicos da sociedade. 
Essas definições são importantes para identificar quais as melhores ferramentas de comunicação a serem adotadas para a obtenção dos objetivos traçados, considerando que, na maior parte dos casos, será necessária a utilização de um mix de instrumentos, pois as abordagens isoladas tendem a ser menos eficientes do que as estratégias de abordagens múltiplas. Como o foco do processo de comunicação é a promoção do relacionamento, os instrumentos a serem adotados devem seguir essa perspectiva inclusiva, englobando tanto suas potencialidades de divulgação e disseminação das informações, que garantem transparência às ações públicas, como suas potencialidades de participação efetiva por meio de reuniões e encontros, presenciais ou virtuais, que viabilizem a troca de informações e a expressão das opiniões.

A Comunicação Pública, sob esta perspectiva, tem um grande desafio a ser vencido, pois estará atuando diretamente na formação de um novo modelo de esfera pública, mais democrática e participativa. Se atualmente a esfera pública está "feudalizada", na perspectiva habermasiana, ao passar a contar com o auxílio de canais de comunicação que não estão exclusivamente focados nos veículos de comunicação de massa, a prática da comunicação pública, quando conduzida de forma ética e responsável, tem a possibilidade de promover e consolidar o engajamento ativo dos cidadãos nas definições e implantações de políticas públicas.

\section{Bibliografia}

AVRITZER, L. A participação em São Paulo. São Paulo: UNESP, 2004.

ARAÚJJO, V. C. A conceituação de governabilidade e governança, da sua relação entre si e com o conjunto da reforma do Estado e do seu aparelho. Brasília: ENAP, 2002.

BAUMAN, Z. Modernidade líquida. Rio de Janeiro: Jorge Zahar, 2001.

BENTO, L. V. Governança e governabilidade na reforma do Estado: entre eficiência e democratização. Barueri, SP: Manole, 2003.

BRESSER PERREIRA, L. C. Reforma do Estado para a cidadania: a reforma gerencial brasileira na perspectiva internacional. Brasília: ENAP, 1998.

CARVALHO, J. M. Cidadania no Brasil: o longo caminho. Rio de Janeiro: Civilização Brasileira, 2002.

ESTEVES. J. P. Espaço público e democracia. São Leopoldo (RS): Editora Unisinos, 2003. p. 27-70.

HABERMAS, J. L'espace public, 30 ans après. Quaderne n 18, Automne, 1992.

HABERMAS, J. Mudança estrutural da esfera pública. Rio de Janeiro: Tempo Brasileiro, 1984.

KONDO, S. et. al. Transparência e responsabilização no setor público: fazendo acontecer. Brasília: MARE, 2002. (Coleção Gestão Pública) 
O PAPEL INSTITUCIONAL DA COMUNICAÇÃO PÚBLICA PARA O SUCESSO DA GOVERNANÇA • ANA LUCIA C. ROMERO NOVELLI

LARA, M. As sete portas da comunicação pública. Belo Horizonte: Gutenberg, 2003.

MARTINS, L. Crise de poder, governabilidade e governança. In: J. P. R. Velloso e R. C. Albuquerque (coord.) Governabilidade e reformas. Rio de Janeiro: José Olympio Ed., 1995. p. 80-86.

MATOS, H. Comunicação pública: democracia e cidadania. Texto apresentado no I Seminário de Comunicação Legislativa. Brasília: Senado Federal, 1998.

OLIVEIRA, M. J. (org.) Comunicação pública. Campinas: Editora Alínea, 2004.

SANTOS JÚNIOR, O. A. (org.) Governança democrática e poder local: a experiência dos conselhos municipais no Brasil. Rio de Janeiro: Revan, 2004.

SANTOS, M.H.C. Governabilidade, governança e capacidade governativa: algumas notas. Brasília: ENAP, 1996.

ZÉMOR, P. La communication publique. Paris: Press Universitaires de France, 1995.

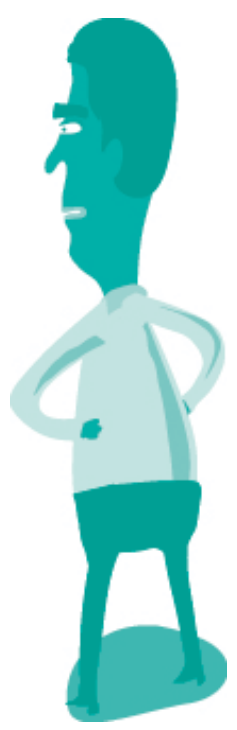

